\title{
A abordagem dialógica e seu influxo nos estudos sobre a linguagem
}

\section{The dialogical approach and its contributions to language studies}

\author{
Tayana Dias de Menezesi (UFPE) \\ Kazue Saito Monteiro de Barros ${ }^{\mathrm{ii}}$ (UFPE)
}

\begin{abstract}
Resumo: O objetivo deste artigo é examinar a abordagem dialógica de Ivana Marková (2006), enfatizando a sua contribuição para as análises linguísticas em geral. A abordagem da psicóloga social insere-se no âmbito da Teoria da Representação Social (TRS), desenvolvida por Serge Moscovici e lapidada por seus discípulos. Pretendemos salientar como os conceitos que alicerçam a TRS são usados para a formação de um modelo de análise capaz de dar conta das relações complexas entre linguagem, cognição e sujeito. Além disso, examinaremos a história e o desenvolvimento do conceito, inicialmente marcada pelos estudos sobre a representação coletiva em Durkheim (1994; 2001).
\end{abstract}

Palavras-chave: Teoria da Representação Social (TRS); Abordagem dialogal; Linguagem; Cognição; Sujeito.

\begin{abstract}
This paper aims at reviewing Ivana Marková's dialogic approach of language, discussing the productivity of this perspective for general linguistics analysis. The social psychologist's approach is part of the Theory of Social Representation, created by Serge Moscovici and refined by his disciples. We intend to highlight how the concepts of this theory are used to form an analytical framework that is capable of accounting for the complex relationships between language, cognition and subject. In addition, we will examine the history and development of the concept, initially marked by studies on collective representation in Durkheim (1994; 2001).

Keywords: Theory of Social Representation; Dialogic approach; Language; Cognition; Subject.
\end{abstract}

\section{Introdução}


O trabalho é orientado teoricamente pela Teoria das Representações Sociais (TRS), desenvolvida por Moscovici e enriquecida pelas abordagens desenvolvidas pelos seus discípulos, a saber: a abordagem culturalista, desenvolvida por Jodelet; a abordagem estruturalista, desenvolvida por Abric; a abordagem societal, desenvolvida por Doise e a abordagem dialógica, desenvolvida por Marková. Examinaremos, com mais atenção, a última abordagem. Além disso, discutiremos a sua produtividade para as análises linguísticas na tentativa de dar conta das relações complexas entre a cognição, sujeito e linguagem. Entendemos a linguagem, conforme Marcuschi (2002), como um sistema simbólico, um elemento constitutivo do conhecimento, responsável pela enunciação e compreensão da realidade social.

A TRS é hoje estudada e discutida nos mais diversos campos do conhecimento: na psicologia, na sociologia, na antropologia, na história, dentre outros e pode contribuir sobremaneira nos estudos linguísticos, especialmente nos estudos discursivos. Isso porque ela nos ajuda a compreender e explicar como os sujeitos e os grupos sociais (re)constroem os conjuntos de conhecimentos necessários para entender o mundo e agir sobre ele e sobre os outros. O artigo é relevante porque revisa conceitos-chave da teoria de Moscovici, considerada a grande teoria dentro da TRS, e lança luz sobre as renovações epistemológicas da abordagem dialogal. Concordamos com Valentim (2013, p. 158): "a necessidade de reflexão teórica parece-me fundamental até para evitar os riscos de trivialização". Valentim (2013, p. 163) defende a vitalidade e importância da TRS sob o argumento: 1) o carácter único da RS, "pelas suas características paradigmáticas, a TRS encontra-se numa posição única, num cruzamento com outras ciências fundamentais para a compreensão dos fenômenos humanos nas sociedades". Em outras palavras, a exposição das bases epistemológicas da TRS é de valia para os pesquisadores interessados nos fenômenos sociais, linguísticos etc. Além disso, o artigo ratifica a interdependência entre cognição, linguagem e sujeito e discute essa relação.

$\mathrm{Na}$ TRS, a realidade social e o comportamento individual estão correlacionados, isto é, os fatos sociais interferem no comportamento individual, mas os sujeitos participam ativamente na (re)construção da realidade. Para Moscovici (2015), as representações ganham vida no cotidiano e são "sustentadas pelas influências sociais 
da comunicação [...] e servem como o principal meio para estabelecer as associações com as quais nós nos ligamos uns aos outros" (MOSCOVICl, 2015, p.8). Podemos perceber que Moscovici (2015) reconhece a contribuição da "comunicação" para a (re)construção da realidade. Marková (2006, p. 268), por sua vez, também defende a importância dos "gêneros de comunicação" para os estudos da RS. A TRS é uma teoria ampla que engloba outras abordagens que complementam os conceitos e as lacunas deixadas por Moscovici. No artigo, examinaremos a história e o desenvolvimento do conceito sobre a representação, inicialmente marcado pelos estudos sobre a Representação Coletiva em Durkheim (1994; 2001). Faremos referência a alguns conceitos-chave da TRS e outros fundamentais das abordagens dos discípulos de Moscovici porque entendemos que eles são imprescindíveis para a compreensão da Representação Social (RS) e, consequentemente, fundamentais para a compreensão da teoria de Marková.

\section{O percurso histórico da TRS}

O conceito Representações Coletivas foi inicialmente introduzido na França, em 1898, por Emile Durkheim. No entanto, por mais de cinquenta anos, caiu em desuso. Mas, por volta dos anos 6o, Moscovici retomou os estudos sobre o assunto e propôs a mudança de Representação Coletiva para Representação Social. Esta não foi apenas uma mudança de nomenclatura, antes marca profundas alterações teóricas. No entanto, Durkheim não partiu do nada, antes deste, filósofos como Kant e Renouvier já pensavam sobre o assunto.

Historicamente, as ideias são compreendidas ou como provenientes do cérebro ou da realidade, ou seja, são ou constructos mentais - reflexo do real - ou fatos sociais. Para Kant, as representações são formadas a partir da percepção do mundo real. Ele "acreditava que a mente cogniza o mundo somente de forma indireta. Ela combina os dados sensoriais em representações de objetos, construindo, portanto, as aparências do mundo" (MARKOVÁ, 2006, p.173). Essas aparências da realidade existiriam apenas na mente. O filósofo Renouvier rejeitou a teoria kantiana de que a mente só tem acesso às aparências do mundo e não à realidade em si. Conforme Marková (2006), possivelmente foi Renouvier quem primeiro propôs publicamente a ideia de que as 
representações são constructos sociais e não mentais, pois para que haja consenso é necessário que haja compartilhamento entre os sujeitos que fazem parte de um grupo. Aparentemente, o caminho estava pronto para o surgimento e acolhimento das ideias de Durkheim.

Conhecer a realidade, para Durkheim, só seria possível por meio das Representações Coletivas. Elas serviam como mediadoras entre o mundo externo e o indivíduo. Os sujeitos teriam acesso à realidade, não por meio das representações mentais, mas por meio da experiência social. Para Durkheim, "as representações são geradas coletivamente na vida social. Elas são a chave ao conhecimento, à lógica e ao entendimento do ser humano" (MARKOVÁ, 2006, p.175). Durkheim (1994) se opõe a ideia de que a sociedade é um mero epifenômeno da vida individual da mesma maneira que a representação individual seria um epifenômeno da vida física, isso porque se assim fosse, a realidade social estaria limitada apenas ao que o indivíduo the comunica e as representações seriam diretamente produzidas por vibrações celulares.

Durkheim (1994) fez referência a uma autonomia relativa entre o indivíduo e a sociedade posto que não há reinos que não se vinculem a outros reinos. As representações estão ligadas à trama da vida social já que a sociedade é um sistema formado pela união entre indivíduos. Durkheim (1994, p. 33) enxergava as representações coletivas como "consciências elementares das quais é feita a sociedade". Para ele, não se podia contestar que os indivíduos são obrigatoriamente influenciados por crenças e práticas religiosas, por regras morais, pelos preceitos do direito, ou seja, pelo que ele chama das "manifestações mais características da vida coletiva" (DURKHEIM, 1994, p.33). As representações coletivas, por sua vez, são exteriores com relação à consciência individual porque não derivam do indivíduo, mas do corpo social que estes fazem parte. Seria incoerente, segundo Durkheim (1994) explicar o complexo pelo simples, o superior pelo inferior, o todo pela parte. Assim como o inverso também não se sustenta: explicar a parte do todo, porque o todo nada é sem as partes que o formam. Dessa maneira, a única possível saída é "explicar os fenômenos que se produzem no todo pelas propriedades características do todo, o complexo pelo complexo, os fatos sociais pela sociedade, os fatos vitais e mentais pelas combinações sui generis de que resultam" (DURKHEIM, 1994, p.37). 
Para Durkheim $(1893,1895,1898)$, as representações coletivas são distintas das representações individuais. Estas são demasiadamente variáveis e ligeiras, estão fincadas na consciência do indivíduo, já aquelas são impessoais, estáveis (o tempo não é um elemento que deve ser levado em conta) e são sustentadas por todo o corpo social, portanto, são homogêneas e partilhadas por todos os sujeitos que compõe a sociedade. Durkheim defende que as representações coletivas são a força de conexão e conservação da sociedade, são elas que conservam a sociedade de fragmentação ou desintegração - aqui, é importante apontar um ponto substancial de afastamento entre as teorias durkheimianas e moscovicianas: enquanto a primeira encara o fenômeno a partir de uma perspectiva estática, a segunda o encara sob uma perspectiva dinâmica.

Marková (2006) aponta para algumas características importantes do pensamento de Durkheim: dualidade da natureza humana, estabilidade das representações coletivas, natureza institucional e repressora das Representações Coletivas - esta característica, como veremos mais adiante, aproxima o conceito representações coletivas do conceito fato social em Durkheim - e monologismo das representações esta última característica está relacionada à natureza repressora do fenômeno.

Sobre a primeira característica, a dualidade da natureza humana, Durkheim considerava o corpo e a mente como dois componentes opostos da natureza humana. Esse dualismo foi estendido para sociedade e indivíduo. As ciências que se ocupam do indivíduo são distintas das que se ocupam dos fenômenos sociais. Por isso representações individuais e representações coletivas são fenômenos diferentes. A primeira são fenômenos psicológicos e neurológicos, são o resultado da natureza física e biológica do indivíduo. As representações coletivas, por sua vez, surgem das estruturas sociais, "elas incluem todos os fenômenos socialmente produzidos que circulam e são compartilhados na sociedade, como religiões, mitos, ciência e linguagem" (MARKOVÁ, 2006, p. 177). Para compreender a representação coletiva, é importante discutir sobre um conceito próximo: fatos sociais.

\section{O que são fatos sociais para Durkheim}


Durkheim (2001) dicotomiza os fatos sociais dos fenômenos individuais; "o fato social é distinto das suas repercussões individuais" (p.36). Isso não significa afirmar que ele não reconhece nenhuma ligação entre estes: "o estreito parentesco entre a vida e a estrutura [...] pode ser facilmente estabelecido em sociologia visto que entre estes dois termos extremos existe toda uma série de intermediários imediatamente observáveis" [grifo nosso] (DURKHEIM, 2001, p.40). Na citação, Durkheim trata os termos como "extremos", ou seja, distintos, mas vinculados. Isso porque, para ele, o fato social caracteriza-se especialmente pela sua exterioridade em relação à consciência individual e pela força coerciva que exerce sobre essa mesma consciência. Para explicar o fato social e o seu poder coercivo, Durkheim (2001) diz que um homem ao cumprir o seu papel social de esposo, de pai ou de cidadão, mesmo que o faça de boa vontade e de acordo com os seus sentimentos, ele cumpre os seus deveres que estão além dele, além dos seus atos, mas estão predefinidos no direito e no costume. O sistema linguístico, o sistema monetário etc. funcionam independentemente do uso que um indivíduo faça deles, pois não foram estabelecidos por ele, antes os sujeitos os recebem por educação. Durkheim (2001) compara o fato social ao sistema linguístico e monetário que existe e funciona independente da vontade do indivíduo. Aqueles existem antes dos indivíduos e "existem fora deles" (Durkheim, 2001, p.132). Se as regras sociais forem violadas, estas reagem contra o seu infrator.

A preexistência dos fatos sociais levanta um ponto importante: estes só existem onde houver organização definida, isso se dá porque as regras jurídicas, as regras morais, os dogmas religiosos etc. se "constituem todos em crenças e práticas constituídas" (Durkheim, 2001, p.34). Para o filósofo, o sujeitos aprendem a ver, a sentir, a agir de uma maneira específica conforme padrões organizados socialmente. Durkheim (2001), no entanto, não considera as consciências particulares ou individuais um fato social.

Podemos concluir, portanto, que segundo a visão durkheimiana, o fato social tem uma existência própria dentro de uma dada sociedade independente das manifestações individuais e exerce sobre os sujeitos um poder coercivo. É possível enxergar os pontos de convergência e uma relação estreita entre os conceitos representações coletivas e fatos sociais em Durkheim. Os fatos sociais são 
independentes dos indivíduos, são construções que se dão na vida social e exercem nos sujeitos um poder coercivo. As representações coletivas, por sua vez, também são independentes do indivíduo, ou seja, são independentes do pensamento individual e são a força de conservação da sociedade, uma vez que são compartilhadas por todos os seus membros. Os fatos sociais, portanto, sustentariam as próprias representações coletivas, uma vez que aqueles preexistem em relação aos sujeitos, organizam a sociedade e os sistemas que dela fazem parte e, como já dito, exercem uma força (tanto de prescrição como de sansão) sobre o comportamento do próprio sujeito social - esse conceito será retomado mais adiante, no entanto sob a perspectiva da TRS. Para Durkheim, como os fatos sociais impõem restrições e sansões aos indivíduos, eles os adotam através de processos de internalização, ou seja, mesmo que as normas e as sanções outorgadas pela sociedade sejam externas ao indivíduo, como sujeitos sociais, eles apreendem os fatos sociais. A sociologia do conhecimento de Durkheim está sustentada no "conceito de representações coletivas estáveis que se reproduzem através do processo de internalização nos indivíduos" (MARKOVÁ, 2006, p. 179).

Os pensamentos de Durkheim influenciaram Moscovici, no entanto há grandes diferenças entre os conceitos representação coletiva e representação social. O primeiro conceito é estático e homogêneo e serve para manter a sociedade integrada como um todo. A RS, por sua vez, é um conceito dinâmico e heterogêneo. Até aqui, discutimos o pensamento do precursor da teoria moscoviciana. Na próxima seção, discutiremos as bases do pensamento de Moscovici $(1978 ;$ 2015) para depois discutir Marková (2006) e analisar as contribuições da TRS para a linguística.

\section{Os fundamentos epistemológicos da TRS}

A Representação social (RS), na TRS, medeia a relação dos sujeitos sociais com os objetos do mundo, sejam eles de natureza material; ideal ou social. Isso significa dizer que é por meio da RS que os sujeitos têm acesso à realidade, ela quem atribui significado aos objetos que circundam os indivíduos. Por esse motivo, Jodelet (2005) classifica a RS como um conhecimento prático, porque ela "serve para se agir sobre o mundo e sobre outros" (JODELET, 2005, p. 43-45). A representação é simultaneamente 
uma (re)construção do próprio indivíduo, uma vez que aspectos motivacionais e intrapsíquicos estão envolvidos no processo, e uma (re)construção social, uma vez que questões de pertencimento grupal também estão envolvidos. Desta forma, podemos concluir que a RS é um fenômeno de dupla natureza: cognitiva e social. Isto é, ela é cognitiva porque a representação é um amálgama de conhecimentos selecionados de maneira motivada pelos sujeitos, além disso, os mecanismos de (re)construção dela se dão na mente. Por fim, ela é social porque parte dos conhecimentos que formam a RS são crenças, ideologias etc., ou seja, conhecimentos socialmente compartilhados. Além disso, as práticas sociais, inclusive as discursivas, são responsáveis pela gênese, perpetuação e modificação das RS.

Na TRS, a noção de sujeito é concomitantemente atravessada pela alteridade o sujeito é ao mesmo tempo constituinte e constituído pelo outro, "eu me projeto nele e ele em mim" (JODELET, 2017, p. 116) - ; pela noção do indivíduo único por conta de suas experiências, embora Jodelet (2017, p. 115) reconheça que a "existência de um sujeito não implica supor nele um estado solipsista" e, por fim, pela noção de agência, o sujeito como um ser "pensante e ativo" (JODELET, 2017, p. 114). Jodelet (2017) esclarece que a multiplicidade de noção sobre o sujeito se dá por conta das esferas de pertença da RS: a da subjetividade; a da intersubjetividade e da trasubjetividade. A primeira diz respeito aos processos que operam no nível individual. O segundo, por sua vez, diz respeito aos processos interacionais entre os sujeitos. E por fim, o terceiro diz respeito aos processos que atravessam o indivíduo, a relação entre eles - ou seja, os sujeitos em sociedade -, o contexto interacional e as produções discursivas. A noção de sujeito atravessa o conceito complexo de RS, tomada como um conjunto de diferentes tipos de conhecimento, experiências individuais, conhecimentos socialmente compartilhados etc., de natureza cognitiva e social.

A representação não acomoda a noção de verdade. Os conhecimentos, que organizam a (re)construção da RS, podem ser, em parte, omitidos; subvertidos etc. pelos sujeitos que selecionam as informações que lhes são de interesse. Em outras palavras, a RS não é um dado, mas resultado de um processo cognitivo e interacional. Por isso, Moscovici (2005) defende que a RS não serve como um espelho para a realidade. Alaya (2014, p. 359) complementa: "as representações não fazem apenas 
representar o real, eles lhe dão forma [...]. A informação recebida é transformada. Portanto, há um vaivém de informações, uma interação entre representação e a realidade". Imersos em um complexo sistema de crenças e sistemas ideológico, os sujeitos (re)constroem a realidade por meio da RS e, ao mesmo tempo, eles são também modificados, assim como a sua relação com o outro. Disto deriva a noção da relação ternária de Moscovici (2015): sujeito- objeto- outro.

Moscovici (2015) aponta dois mecanismos fundamentais para (re)construção da RS: a objetivação e a ancoragem. O segundo é responsável pela acomodação do novo dentro da organização categorial que os sujeitos já possuem dos mais diversos objetos que circundam a realidade. A ancoragem é responsável pela dinamicidade do processo representacional. Isso porque, ao acomodar o novo num grupo categorial específico, muda-se o grupo e a relação deste com os demais. Ou seja, muda-se todo o sistema organizacional cognitivo do indivíduo. Neste processo, os sujeitos comparam o novo, seja um objeto; uma pessoa; um evento etc., com um elemento prototípico de um grupo específico. Essa comparação não segue parâmetros lógicos, mas segue os interesses dos sujeitos que podem tornar um aspecto relevante e sombrear outros. A objetivação, por sua vez, é o processo responsável por dar forma a uma RS, ou seja, é reproduzir um conceito a uma imagem, segundo Moscovici (2015). Para exemplificar, Herzlich e Pierret (2005) estudaram a AIDS, enquanto fenômeno social, por meio de artigos publicados em seis jornais franceses entre os anos de 1982 a 1986 . Elas concluem que a doença estava ancorada em noções como: "câncer misterioso nos homossexuais americanos"; "a pneumonia dos homossexuais"; "câncer gay" etc. À medida que os conhecimentos científicos sobre a AIDS avançavam, a ancoragem sobre a doença também sofria mudanças.

A ancoragem explica a gênese e a dinâmica do processo representacional, como mencionado acima. No entanto, foi seu discípulo Abric quem explicou como a RS pode ser, ao mesmo tempo, resistente a mudanças, mas flexível e adaptável ao contexto. A sua estrutura interna lança luz sobre essa aparente contradição. A RS possui dois sistemas: um núcleo central, parte mais estável da representação, e o sistema periférico, parte mais flexível e maleável da representação e responsável pela proteção do núcleo. É o sistema periférico quem absorve e modela informações que contradizem 
o núcleo. Segundo Abric (2003) e Flament (2001), ele serve como um tipo de parachoque para o núcleo. Sendo assim, o núcleo central conserva os significados mais profundos da RS enquanto o sistema periférico o protege, adaptando-se ao contexto imediato.

Discutimos brevemente os conceitos basilares da TRS. Na próxima seção, discutiremos a base teórica da abordagem dialógica de Marková (2006).

\section{A abordagem dialógica}

Faz parte da capacidade humana, segundo Marková (2006), fazer distinções e esta é fundamental para a vida, para o pensamento e para a comunicação humana. Se observarmos o pensamento da humanidade ao longo da história e em diferentes culturas, vamos nos deparar com uma série de antinomias como bom/ mal; vida/ morte; saúde/ doença; moral/ imoral. A Teoria de Marková (2006) se concentra nos conceitos: themata e antinomias dialógicas, embora toda themata seja uma antinomia nem toda antinomia se constitui em themata. Para Marková (2006, p.252), a themata "nos remete às antinomias do pensamento [...] que modelam as atividades mentais dos humanos", enquanto antinomias corresponde à "discriminação entre opostos" (MARKOVÁ, 2006, p.55). Para que uma antinomia se transforme numa themata, ela precisa ganhar saliência social, ou seja, suscitar debate no discurso público. Marková (2006) explica que "as antinomias [...] se tornam themata se, no curso de certos eventos sociais e históricos, isto é, políticos, econômicos, religiosos, etc., elas se tornam em problemas e se tornam o foco da atenção e a fonte de tensão e conflito" (p. 252). Por estarem no âmago do pensamento social, elas orientam a maneira como os indivíduos categorizam os objetos que fazem parte da realidade.

Embora não existam evidências de que fazer distinções e o pensamento tenham as mesmas origens na inteligência humana, Marková (2006) defende que a capacidade de fazer distinções é essencial para os humanos. Para sustentar seu ponto de vista, Marková (2006) faz uma retrospectiva do pensamento filosófico e científico desde a antiga Grécia, passando pela China, pelo Renascimento e por pensadores como: Kant, 
Hegel, Jung, Freud, dentre outros. No entanto, a autora distingue "diferença" de "antinomia" e para isso usa um dos binômios saussurianos: la langue (língua) e la parole (fala). Saussure (2004) faz essa distinção para delinear qual seria o seu objeto de pesquisa: a fala "é a soma do que as pessoas dizem, [...] combinações individuais" (SAUSSURE, 2004, p. 27, 28), enquanto a língua "é [...] um produto social da faculdade de linguagem e um conjunto de convenções [...] adotadas pelo corpo social" (SAUSSURE, 2004, p. 17). Para o linguista, a fala não pode ser objeto da ciência porque ela é demasiadamente variável, mas a língua é um sistema e como tal pode ser analisado. Portanto, apesar de diferentes, os conceitos de língua e fala não são opostos, fazem parte de uma mesma categoria: a linguagem. Ambas são facetas diferentes da linguagem. São diferentes, mas não se configuram em antinomias. Essa distinção é fundamental e iremos retomá-la mais adiante para entender o posicionamento da psicóloga social.

Marková (2006, p. 60) aponta que as antinomias do pensamento podem ser de diferentes espécies e conclui que "os critérios usados para a classificação dos opostos, contrários, contraditórios, dualidades e polaridades, representam uma enorme variedade e são baseados em muitas qualidades diferentes do fenômeno em questão" [grifo nosso]. A parte em negrito destaca que ela usa os termos como sinônimos, ou seja, Marková (2006) não deixa claro, na sua teoria, a diferença entre pares de opostos, dualidades, polaridades... No entanto, em outro momento, ela afirma que "termos como "antinomia", "oposição", polaridade", "par", "dualidade" etc. têm significados diferentes e heterogêneos (MARKOVÁ, 2006, p.6o). Ainda assim, não deixa claro que significados são esses e na citação marcada usa os termos como intercambiáveis.

Marková (2006, p. 248) afirma que themata são conceitos dialógicos. Para Bakhtin, por sua vez, a palavra é atravessada pela luta entre as diversas vozes que ecoam socialmente. Ela é, em parte, retrato da interação entre o eu e o outro e signo ideológico, "cada palavra se apresenta como uma arena em miniatura onde se entrecruzam e lutam os valores sociais de orientação contraditória" (BAKHTIN, 2018, p.47). As antinomias e as thematas são, em parte, o resultado desse embate social. A palavra, por sua vez, é um lugar privilegiado para observar o fenômeno. 
Apoiando-se em Moscovici, Marková (2006, p. 252) propõe que a themata está presente no pensamento de senso comum e alicerça a (re)construção da RS. No entanto, aponta que eventos históricos podem ressignificar uma antinomia, para exemplificar: o que antes era categorizado como comestível - uma antinomia (comestível/ não comestível) sustentada pela themata do limpo/ sujo -, depois do desastre de Chernobyl, a doença da vaca louca etc., pode-se transformar em não comestível.

No que diz respeito a antinomias que podem se tornar thematas, os exemplos que Marková explora são interessantes, mas por vezes pouco esclarecedores, ex.: cores como thema, azul/ não azul. O que seria o não azul? Vermelho; preto; rosa... uma infinidade de cores não pode ser tomada como uma antinomia de uma cor específica, muito menos a sua negação - não azul. Marková (2006) fala da antinomia azul/ não azul e como argumento utiliza os significados simbólicos historicamente compartilhados em sociedades distintas. Reflete sobre a significância social e mística que esta cor tinha no Egito. Na Grécia e em Roma a situação era diferente, não havia nem uma palavra que distinguisse o azul do violeta, do verde ou de outra cor, estar vestido de azul significava inferioridade ou excentricidade. No entanto, isso mudou; o azul passou a ser a cor das vestes da Virgem Maria, tornou-se um simbolismo religioso. A cor passou também a ter relevância na arte. O azul ganhou relevo social, foi simbolicamente ressignificado no curso da história, mas qual é a antinomia de oposição que serve de sustentáculo para o pensamento social em relação à referida cor? O azul/ não azul é uma distinção perceptual, mas não se configura numa themata. Pode-se pensar que, em eventos históricos específicos, como a revolução francesa, o azul simbolizava a liberdade. Por isso, a cor pode evocar a themata liberdade/ opressão que orienta o pensamento social e serve como base para a (re)construção de muitas representações sociais. Liberdade/ opressão pode ser definida como uma themata pois são antinomias que orientam o pensamento social, no entanto azul/ não azul não são nem pares de opostos, mas uma simples negação. Essa confusão teórica se dá porque faltam definições mais precisas em relação à distinção entre antinomia de pensamento, pares de oposição, dualidade etc. Para ratificar o porquê não consideramos azul/ não azul como uma antinomia de oposição: igualdade/ desigualdade não possuem um leque de 
possibilidades dentro da categoria em que pertencem. Alguém que não é tratado com igualdade é, consequentemente, tratado com desigualdade, mas se uma cor não pertence a categoria azul, há uma variedade imensa de possibilidades para o não azul: verde; rosa; roxo etc. Isso significa que azul/ amarelo são antinomias de oposição? Pode-se considerar preto/ branco uma antinomia de oposição porque enquanto uma é ausência total de luz a outra é luz pura. Azul/ não azul, portanto, são apenas um par de negativa. Marková (2006) usa um outro argumento: não existe um padrão para o tom azul usado na bandeira nacional escocesa, isso causa discussão entre o parlamento que se recusa a escolher um único tom. Voltamos à pergunta inicial: qual a antinomia que o pensamento apresenta? Parece-nos inconsistente falar de uma antinomia entre diferentes tons de azul. Embora, o exemplo dado pela autora seja frágil no que diz refeito à cor azul como uma antinomia de oposição, há uma questão relevante neste exemplo que resgataremos nas conclusões.

A psicóloga social estabelece uma oposição baseada numa simples negativa. Dentro da categoria não azul pode-se incluir o vermelho - que possui uma série de significados simbólicos como: paixão, comunismo, sangue, morte etc. -; o laranja; 0 verde e todas as outras cores que não fossem o azul. Ou seja, houve uma diferenciação - neste momento, devemos lembrar que a própria Marková distingue diferença e antinomia (usando elementos da teoria de Saussure) - entre uma cor específica e outras que estão dentro de um mesmo conjunto de categorias: cores. A diferença, além de sensorial, são os significados simbólicos que cada uma agrega para si, isso faz parte das crenças, valores e história de sociedades específicas.

Outro exemplo dado é o do reconhecimento social como thema básica. Conforme Marková (2006), a história pode ser analisada pela busca dele e, como thema básica, evoca outras thematas. A autora faz uma análise instigante que nos auxilia a compreender alguns pontos fundamentais de sua teoria. Segundo a psicóloga polonesa, algumas thematas ganham, na vida social, maior relevo que outras, umas são "quase eternamente enfatizadas nos discursos públicos, enquanto outras emergem, sobrevivem por algum tempo e desaparecem" (MARKOVÁ, 2006, p.258). Ela analisa como esse thema, o reconhecimento social, fez emergir discursos distintos que em conexão com outras thematas - nós/eles, liberdade/opressão, justiça/injustiça e 
igualdade/ desigualdade -, gerando, dentro de uma sociedade, o conflito. Além disso, o reconhecimento social é considerado thema básico porque "é um esforço social básico - ou desejo" (MARKOVÁ, 2006, p.258). Para exemplificar: um pedaço de papel ou uma medalha, aparentemente sem valor financeiro, podem ser tidos como objetos de desejo porque simbolizam reconhecimento social. Como mencionado anteriormente, a thema do reconhecimento social evoca thematas diversas. Historicamente, ele passou por mudanças de perspectivas: da honra para a dignidade, num processo de thematização. Marková (2006, p.261) defende que "o reconhecimento social é expresso através dos períodos da história em diferentes termos, no curso da modernidade o mesmo tem sido analisado através da transição do conceito de honra para a dignidade". A honra, entendida como reconhecimento social, existiu em sociedades medievais como código de conduta e status determinado pelo nascimento, ela mantinha a ordem hierárquica e foi, também, objeto de discussão na arte em Shakespeare, em Molière etc.

Mas, no decorrer da história, e com a mudança no regime que dita o código de comportamento, a honra foi substituída pela noção de dignidade. O merecimento ao reconhecimento social deixa de ser determinado pelo nascimento e passa a ser uma conquista do indivíduo: "a Themata igualdade/ desigualdade, liberdade/ opressão e justiça/ injustiça, se tornam problematizadas e thematizadas na vida diária" (MARKOVÁ, 2006, p.261). O diálogo suscita, num momento histórico determinado, 0 conflito ou o processo de thematização. Isso faz emergir, dentro do discurso público, antinomias de oposição que estão enraizadas no pensamento humano. Estas se tornam um problema de relevância social ou themata. Um coro de vozes emerge no discurso público para lutar e marcar suas posições, o diálogo entre o eu e o outro se configura por tomadas de posição dentro da realidade social.

Como salientado anteriormente, a abordagem de Marková apresenta uma perspectiva inovadora dentro do âmbito da TRS sobre a ancoragem da RS, levando em conta o discurso. Ela é marcada por antinomias dialógicas que devem ser analisadas a partir das crenças, das ideologias etc. que configuram uma dada sociedade em um momento histórico. Ela dá conta também do embate entre as vozes que marcam os discursos que circulam socialmente. No entanto, como foi discutido acima é preciso 
delinear mais precisamente os contornos da definição teórica de antinomias, posto que este está na base para a compreensão de outros conceitos- chave que circundam a teoria, como a themata.

\section{A relação entre a RS e a linguagem: considerações finais}

A abordagem dialógica de Marková (2006), como discutido, gira em torno do conceito themata e antinomias dialógicas. Embora o segundo careça de precisão conceitual, a themata diz respeito aos pares de opostos que organizam os elementos que ancoram uma RS. Elas, também, orientam a maneira como os indivíduos categorizam os objetos que fazem parte da realidade. Os "gêneros de comunicação" (MARKOVÁ, 2006, p. 268), são um lugar privilegiado para se estudar o fenômeno. Por isso defendemos, a partir do que foi exposto, que os estudos orientados pela TRS, especialmente pela abordagem dialógica de Marková, contribuem para os estudos linguísticos, principalmente aqueles guiados por uma perspectiva sociocognitivista da linguagem. A abordagem de Marková foca "na interação e interdependência entre Ego e os Outros, e em sua experiência engajada, no conhecimento e comunicação na vida cotidiana" (MARKOVÁ, 2017, p. 23). Ou seja, A TRS esclarece como os sujeitos, seres cognitivos e sociais, entendem e anunciam as suas realidades. A relação entre os sujeitos, o corpo social e a realidade é mediada pela linguagem, enquanto uma forma de cognição sócio-histórica, e pela RS, enquanto um amálgama de conhecimentos de natureza diversa que auxilia os sujeitos a se posicionarem socialmente e agir em esferas específicas de atuação.

Como enfatizado, a abordagem dialógica se concentra no conceito de themata. O processo de thematização, por sua vez, acontece no discurso público e é responsável pela (re)construção dos conhecimentos socialmente compartilhados. Além disso é, em parte, responsável pelo processo de ancoragem da própria RS. Isto é, a teoria de Marková procura explicar o processo de (re)significação da RS e, consequentemente, da (re)significação da própria realidade social. Todo o processo se dá por meio do discurso, o lugar de embate entre as vozes sociais, e é por meio da língua que (re)construímos nossos conhecimentos sobre a realidade. Marková (2017, p. 362) defende que: 
communication and language are phenomena based on various kinds of tension between speakers and listeners essential to the concept of social representations. Representations are formed, maintained and changed in and through language and communication and equally, the use of words and attributes attached to meanings transforms social representations ${ }^{1}$.

Marková (2017), na citação, defende a importância das relações interacionais, especialmente as tensões entre os sujeitos sociais que se dão na e por meio da linguagem e são responsáveis pela manutenção ou perpetuação dos significados que ancoram a RS. A themata dá conta desse processo de tripla natureza: cognitivo; social e discursivo.

Ao longo do artigo, expusemos a interrelação entre os sujeitos, a cognição e a linguagem dentro da TRS, especialmente, dentro da abordagem dialógica, que encara a linguagem e o discurso como os lugares privilegiados para compreender o conflito das vozes sociais e os processos representacionais. Em outras palavras, "as representações sociais [...] atuam como a 'interface' necessária entre as interações de nível micro e o texto e a fala individuais, por um lado, e as macroestruturas sociais, por outro" (VAN DIJK, 2015, p. 19). Isso acontece porque a cognição social é responsável pelo monitoramento da produção e interpretação dos discursos.

Discurso, sujeito e cognição estão intimamente relacionados. Falcone (2016) defende que "a nossa forma de perceber, compreender, categorizar e, por fim, construir os 'objetos do mundo' resulta de atividade contínuas e situadas, que se dão na interação social. Assim, trata-se de perceber como as pessoas agem sobre o mundo, no mundo, com o mundo" (p. 6o). Em outras palavras: os sujeitos, entidades cognitivas e sociais, (re)constroem a realidade por meio de processos representacionais, a linguagem perpassa todo o processo. Por isso defendemos que a TRS pode enriquecer os estudos linguísticos e vice-versa. Marcuschi (2002: p. 46) afirma que "sem uma língua não saberíamos produzir nem distribuir conhecimentos", isso ratifica o que acabamos de defender: há uma relação dialética entre a língua e a fabricação de conhecimento, uma

\footnotetext{
1 “comunicação e linguagem são fenômenos baseados em vários tipos de tensão entre falante e ouvinte essenciais para o conceito de representação social. Representações são formadas, mantidas e alteradas na e por meio da linguagem e das comunicações e, igualmente, o uso de palavras e atributos vinculados a significados transformam a representação social [tradução nossa]" (MARKOVÁ, 2017, P. 362).
} 
vez que é na interação que thematizamos as antinomias dialógicas do pensamento, segundo Marková (2006).

A língua não é apenas um sistema de código, "mas se caracteriza como um sistema simbólico de grande plasticidade com o qual podemos dizer criativamente o mundo" (MARCUSCHI, 2002, p. 44). E é justamente sustentado por esse sistema simbólico que construímos os conhecimentos; as crenças; os sistemas ideológicos, isto é, a RS. Mas, a relação também acontece na contramão: a representação que temos dos sujeitos; dos eventos em que nos engajamos, da realidade como um todo nos guia na seleção de língua que usaremos numa situação específica. Sobre o assunto Falcone (2016) comenta:

[...] i)a língua está integrada com a cognição e com a sociedade, encontrando-se no discurso a sua possibilidade de realização; ii) a língua está em evolução contínua, assim como todas as práticas sociais; iii) existem várias 'versões de língua' (ou usos), pois sua realização resulta de diferentes situações, entre diferentes interlocutores; iv) esta perspectiva reconsidera o equilíbrio entre a liberdade do uso da língua versus as convenções da língua de uma comunidade. É dessa forma que, ao usar a língua, as pessoas nunca usam toda a língua, nem mesmo todo o seu conhecimento dessa língua, mas sempre uma 'versão ativada no fluxo do uso da língua', o que dá suporte ao discurso (FALCONE, 2016, p. 60).

Ao usar a língua, os sujeitos selecionam, de acordo com as suas representações, a 'versão de língua' mais adequada para a situação em que se encontram. Para fazerem essa seleção, os sujeitos acionam seus conhecimentos, as representações sobre os objetos do discurso e modelos de contexto. Por isso, ao observar o discurso construído, temos a possibilidade de observar a força propulsora de sua construção, isto é, os conhecimentos acionados e as representações sociais dos objetos do discurso.

Os estudos que levam em conta a RS, enquanto um amálgama de conhecimentos, e sua relação estreita com a linguagem é vasto e, sobremaneira, produtivo. Além das pesquisas de Marková, podemos apontar as da pesquisadora Leitão (2007). Ela investiga o papel mediador da argumentação na (re)construção do conhecimento, sob o sustentáculo das teorias de Bakhtin no que diz respeito à heteroglossia dialógica - o embate entre as diferentes vozes que circulam socialmente. Leitão (2007, p. 79) defende, sustentada por Marková (2006), que a abordagem dialógica "enfatiza a interdependência indivíduo- mundo, indivíduo- indivíduo, 
indivíduo- linguagem, como "condição sine qua non" para a constituição do conhecimento e, de resto, para o funcionamento do próprio psiquismo humano". Em outras palavras, o acesso aos conhecimentos ou à RS socialmente compartilhada entre os sujeitos que integram o corpo social se dá por meio da linguagem. Ainda segundo Leitão (2007, p. 79):

A construção do conhecimento é concebida como um contínuo processo de produção de sentido sobre o mundo (físico, simbólico, social) na relação com o mundo e com a necessária mediação de comunicação, linguagem e outros artefatos culturalmente produzidos (Linell, 2006, p.29). A construção de sentido para a realidade circundante é um processo necessariamente responsivo que implica uma tomada de posição valorativa a respeito dos aspectos do mundo focalizados a cada instante (LEITÃO: 2007, p. 79).

Os estudos baseados na TRS podem lançar luz aos estudos linguísticos (e viceversa) que focalizam a interdependência entre conhecimentos socialmente compartilhados, a linguagem, as práticas sociais e a cognição, uma vez que "processos psicológicos estritamente humanos de pensamento e construção do conhecimento surgem no âmbito de relações dialógicas, cuja natureza é necessariamente sociossemiótica - constituída pela linguagem e outros recursos semióticos [...]" (LEITÃO, 2007, p. 77).

Para concluir a nossa reflexão sobre o influxo da TRS na linguística, usaremos um trecho do romance de Agualusa - o trecho resgata as questões referentes à cor azul proposta por Marková (2006) -, A sociedade dos sonhadores involuntários:

Os antigos gregos, como os chineses ou os hebreus, não tinham uma palavra destinada a designar a cor azul. Para todos eles o mar era verde, acastanhado ou cor de vinho. Eventualmente, negro. $\mathrm{Na}$ pintura ocidental o mar só começou a ser representado a azul no século XV. Também o céu não era azul. Poetas descreviam-no como rosado, ao amanhecer; incendiado, ao lusco-fusco; leitoso, nas melancólicas manhãs de inverno.

Talvez sejam os nomes a dar existência às coisas. [...]. Entretanto sou um pintor que, em plena idade média, escolhesse um certo tom de azul para colorir o mar. Isso antes de existir a palavra azul. Antes de existir a cor azul. Contemplando as telas desse pintor, [...] as pessoas não conseguiriam esconder a estranheza e o horror (AGUALUSA, 2017, p.154-155).

Como expusemos anteriormente, discordamos do exemplo dado por Marková (2006) sobre a cor azul enquanto uma antinomia, no entanto o exemplo sobre a cor é 
interessante para refletirmos na importância do processo de simbolização de uma realidade material em uma RS e a enunciação desta dentro do discurso público. Uma realidade só pode tornar-se familiar e ser incorporada no sistema cognitivo dos sujeitos quando ela ganha corpo dentro do discurso público. "Talvez sejam os nomes a dar existência às coisas"; é o processo de nomeação - processo linguístico, mas também cognitivo, sustentado pelo processo de ancoragem da RS - que torna o estranho familiar, segundo Moscovici (2015). Ou seja, uma realidade material - como a cor azul - apenas existe socialmente quando ela se torna uma realidade social, isto é, quando adentra, por meio da ancoragem, no sistema cognitivo dos sujeitos, como uma RS, e nos discursos que circulam socialmente nas interações cotidianas. "[...] É por meio dela [da língua] que os homens criaram o mundo [...] Deus cria coisas, mas um homem cria nomes. [...] Nomear cria a realidade social dos homens" (MARKOVÁ, 2017, p. 85), neste trecho Marková (2017) ressalta a importância do processo de nomeação para a (re)criação da realidade social. A autora complementa: "nomear é uma atividade social. Somente se os outros aceitam o nome que sugiro para algo em particular é que seu significado se torna uma propriedade comum sobre a qual a comunidade pode agir" (MARKOVÁ, 2017, p. 85). Dessa maneira, não basta a cor azul ser uma realidade material, ela precisa ser nomeada; precisa ser thematizada dentro do discurso público. Assim, a cor se transforma numa realidade social. Portanto, tanto a língua como a RS são fundamentais para que os sujeitos tenham acesso à realidade, tanto no que diz respeito à agência como à compreensão do mundo.

Os estudos, que levam em conta a TRS, nos permitem averiguar as mudanças sociais num duplo sentido, segundo Valentim (2013, p. 164), "o da mudança das próprias representações sociais e o de conceito útil para a compreensão dos processos de transformação social nas sociedades e comunidades". Nesse sentido, o autor aponta o futuro dos estudos guiados pela TRS: aqueles que centralizam a influência da RS nas práticas sociais, especialmente, na naturalização de práticas discriminatórias em relação aos grupos sociais minoritários, como faz Vala (2004; 2010; 2015) sobre as novas expressões racistas, especialmente na sociedade portuguesa. O autor ainda aponta, para o futuro produtivo da TRS, a necessidades de levar em consideração outros "sistemas explicativos" (VALENTIM, 2013, p.163), como a linguagem. Desta forma, 
podemos esperar um futuro longínquo para a TRS, uma vez que "sem a compreensão dos sistemas de significação em jogo, o trabalho de transformação social está condenado ao fracasso" (VALENTIM: 2013, p. 164).

\section{Referências bibliográficas}

ABRIC, Jean Claude. A abordagem estrutural das Representações Sociais: desenvolvimentos recentes. In: CAMPOS, P.H.; LOUREIRO; M.C.S. Representações Sociais e práticas educativas. ED. UCG, Goiânia, p. 37- 57, 2003.

ABRIC, Jean Claude; RATEAU, Patrick; MOLINER, Pascal; GUIMELLI, Christian. Handbook of Theories of Social Psychology. London, 2012.

ABRIC, Jean C. Metodologia da abordagem Estrutural das Representações Sociais. In: $A B R I C, J . C$ (org.). Méthodes d'atudes des representations sociales. Érès: Ramonville Saint-Agne. Traduzido por Maria de Fátima de Souza Santos para uso de pesquisa.

AGUALUSA, José E. A sociedade dos sonhadores involuntários. São Paulo: Planeta, 2017.

ALAYA, Dorra Bem. Abordagens filosóficas e Teoria das Representações Sociais. In: ALMEIDA, Angela M. de; SANTOS, Maria de Fátima; TRINDADE, Zeide A. (orgs). Teoria das Representações sociais: 50 anos. Brasília, Technopolitik, 2014.

BAKHTIM; VOLÓCHINOV. Maxismo e Filosofia da linguagem: problemas fundamentais do método sociológico na ciência da linguagem. São Paulo: Editora 34, 2018.

DURKHEIM, Emile. As regras do método sociológico. São Paulo: Editora Martin Claret, 2001.

DURKHEIM, Emile. Sociologia e filosofia. São Paulo: Ícone, 1994.

FALCONE, Karina. O discurso da mídia: legitimação e categorização social. Recife: Editora UFPE, 2016.

FLAMENT, Claude. Estruturas e Dinâmicas da Representações Sociais. In: Jodelet, Denise (org.). As representações sociais. Rio de Janeiro: EdUERJ, 2001.

HERZILICH, C.; PIERRET, J. Uma doença no espaço público. A AIDS em seis jornais franceses. PHYSIS: Rer. Saúde Coletiva, Rio de Janeiro, 15 (Suplemento), p. 71- 101, 2005 .

JODELET, Denise. Loucuras e representações sociais. Petrópolis, RJ: Vozes, 2005. 
JODELET, Denise. O encontro dos saberes. In. JESUìNO, Jorge C.; MENDES, Felismina R.P.; LOPES, Manoel José. (orgs). As representações sociais nas sociedades em mudança. Petrópolis, RJ: Vozes, 2015.

JODELET, D. A alteridade como produto e processo psicossocial. Em: A. Arruda (org.). Representando a alteridade. Petrópolis: Vozes, p. 47-67, 1998.

JODELET, D. Representações Sociais e mundos de vida. São Paulo: Fundação Carlos Chagas; Curitiba: PUCPRess, 2017.

KALAMPALIKIS, N. Le processos de 'l'ancrage: I'hypothèse d'une famaliarisation à l'envers. Carnets du GrePS, Université de Lyon, p. 19-25, 2009.

LEITÃO, Selma. Processos de construção do conhecimento: a argumentação em foco. Pro-Posições, Campina, v.18, n 3 (54)- set/dez, 2007.

MARKOVÁ, Ivana. Dialogicidade e representações sociais: as dinâmicas da mente. Petrópolis, RJ: Vozes, 2006.

MARKOVÁ, Ivana. Mentes dialógica: senso comum e ética. Curitiba: PUCPRESS, 2017.

MARKOVÁ, Ivana. The making of the theory of social representations. Cadernos de pesquisa, v. v. 47, n. 163, p. 358-375. Jan/ mar. 2017.

MARCUSCHI, Luiz Antônio. Do código para a cognição: o processo referencial como atividade criativa. Veredas - revista de estudos linguísticos. V. 6, n. 1, p. 43- 62. 2002.

MENEZES. Tayana Dias de. A (re)construção da representação social sobre o surdo e suas marcas discursivas. 2020. Tese (doutorado em Linguística) - Universidade Federal de Pernambuco (UFPE), Recife, 2020.

MOSCOVICl, Serge. A representação social da psicanálise. Rio de Janeiro, Zahar, 1978.

MOSCOVICl, Serge. Representações Sociais: Investigações em psicologia social. Petrópolis, RJ: Vozes, 2015.

SAUSSURE. F. Curso de lingüística geral. 26. ed. São Paulo: Cultrix, 2004.

VALA, Jorge; LIMA, Marcus Eugênio Oliveira. As novas formas de expressão do preconceito e do racismo. Estudos de psicologia, 9 (3), p. 4001- 411, 2004.

VALA, Jorge; PEREIRA, Cícero Roberto. Do preconceito à discriminação Justificada. InMind_Português, vol.1, $\mathrm{n}^{\circ} 2-3,1-13,2010$. 
VALA, Jorge; LOPES, Diniz; BRITO; Rodrigo. Racismo, esteriótipo e emoções: << eles não são piores do que nós, mas nós somos melhores do que eles»>. In: VALA, Jorge; LOPES, Diniz; BRITO; Rodrigo. Expressões dos racismos em Portugal. Lisboa: Imprensa de Ciências Sociais, 2015.

VALENTIM, Joaquim Pires. Que futuro para as representações sociais? Psicologia e Saber Social. Rio de Janeiro. V.2, n 2, 2013.

' Doutora em Linguística pela Universidade Federal de Pernambuco (UFPE). Professora do departamento de Letras na UFPE. Pesquisadora PIBIC, projeto “A voz dos surdos: Representação Social e Memória Coletiva".

ORCID: http://orcid.org/0000-0002-9338-8395.

E-mail: tayana dias@yahoo.com.br.

ii Doutora em Language and Linguistics pela University Essex; mestra em Linguística pela Universidade Federal de Pernambuco (UFPE); graduada em Letras - Português/Inglês pela Universidade Federal do Rio de Janeiro (UFRJ).

ORCID: https://orcid.org/0000-0001-9024-6239.

E-mail: kazuesaito2@gmail.com.

Recebido em 28/og/21

Aprovado em 12/01/22

Todo conteúdo da Revista Eutomia está sob a Licença Creative Commons Atribuição 4.o Internacional. 